\title{
Gender on Animal Nouns in Greek
}

\author{
Giorgos Spathas
}

Leibniz-Zentrum Allgemeine Sprachwissenschaft

g.spathas@gmail.com

Yasutada Sudo

University College London

y.sudo@ucl.ac.uk

Received: November 12, 2019

Accepted: June 26, 2020

\begin{abstract}
In this paper we examine the semantic properties of gender specifications of nouns that describe animals (animal nouns), a topic that has not been given sufficient attention in the literature. Focusing on (Modern) Greek, we observe that different animal nouns have different 'default genders', unlike nouns that describe humans (human nouns), which can only be masculine-default. At first this seems to be a problem for the widely held idea that masculine is unmarked in languages like Greek, but we explain it away by claiming that such cases involve genders with no interpretations, i.e. grammatical genders. However, our observations reveal several key differences between animal and human nouns, which call for further theoretical inquiry.
\end{abstract}

Keywords: gender; markedness; animal nouns; Greek

Resum. Interpretació dels gèneres animals

En aquest treball examinem les propietats semàntiques de les especificacions de gènere dels noms que descriuen animals (noms d'animals), un tema que no ha rebut prou atenció en la bibliografia. Centrant-nos en el grec (modern), observem que els noms d'animals tenen diferents «gèneres per defecte», a diferència dels noms que descriuen els humans (noms d'humans), que per defecte només poden ser masculins. En principi, això sembla un problema per a la idea generalment acceptada que el masculí és la forma no marcada en llengües com el grec, però ho expliquem afirmant que aquests casos impliquen gèneres no interpretables, és a dir gèneres gramaticals. Tot $i$ això, les nostres observacions revelen diverses diferències fonamentals entre els noms d'animals i els noms d'humans, que requereixen una investigació teòrica més completa.

Paraules clau: gènere; marcatge; noms d'animals; grec

\section{Table of Contents}
1. Introduction
4. Towards an Analysis
2. Markedness and Interpretation of
5. Concluding Remarks
Gendered Human Nouns
References

\section{Animal Nouns}




\section{Introduction}

A subset of the world's languages exhibit obligatory nominal agreement whereby different nouns require different forms of items like adjectives, determiners, and verbs that bear certain syntactic relations with them. This phenomenon is widely called gender. Let us illustrate the phenomenon with (Modern) Greek. A noun like kipos 'garden' can be modified by one form of the adjective for 'small', namely mikros, but not by other related forms like mikri and mikro. Similarly, it can occur with one form of the singular nominative definite article $o$ but not with other forms like $i$ and to. On the other hand, avli 'backyard' can cooccur with mikri and $i$, but not with other related forms of these items.

Each noun comes with a specification as to which gender it is compatible with. In the case of Greek this is mostly predictable from the inflectional class of the noun. ${ }^{1}$ In French, the gender is largely predictable from the final segments of the noun, although there are many unpredictable cases (see Corbett 1991; Lowenstamm 2012; Fathi \& Lowenstamm 2016). In (Standard) Dutch, on the other hand, there does not seem to be any reliable morphological or phonological cue on the noun itself about its gender (cf. Tsimpli \& Hulk 2013). For this reason, we define gender in terms of agreement with items like adjectives and articles, and regard inflectional classes as a separate, though potentially related, phenomenon.

This agreement phenomenon is called 'gender' and terms like 'masculine' and 'feminine' are widely used, largely because languages like Greek are rife with cases where relevant agreement appears to correlate with gender-related interpretations. For instance, the noun jatros 'doctor' can agree in 'masculine' or 'feminine', and when agreeing in masculine the noun is often used to describe a male individual while when agreeing in feminine it is used to describe a female individual. Greek has a number of such nouns that can agree in masculine or feminine, which we call epicene nouns here, following Merchant (2014) and others.

In addition to epicene nouns, Greek also has many morphologically related masculine- feminine pairs, for example, athlitis and athlitria, both of which mean 'athlete' but differ in gender inferences. Roughly, the masculine form athlitis is typically used for describing male individuals and the feminine form athlitria for describing female individuals, although there are some complications, as we will discuss in more detail later. In some cases the two nouns that describe male and female versions of the same concept do not bear obvious morphological similarity, e.g. pateras 'father' and mitera 'mother'. Although the genders of these nouns are as expected from their meanings - i.e. pateras is masculine and mitera is feminine - it is a theoretical question whether or not such pairs should be treated on a par with morphologically related pairs like athlitis-athlitria.

As is sometimes remarked, 'gender' is arguably a misleading term, at least in some cases. For example, Greek is said to have three genders, standardly called

1. The exceptions to this are nouns that end in -os in nominative singular and -oi in nominative plural, which can be masculine (e.g. xronos 'time'), feminine (e.g. periodos 'period'), or 'epicene' (e.g. jatros 'doctor'; see below). See Ralli (2000), Alexiadou (2004) for details and Corbett (2000:\$3.1.1) for similar facts about nominal inflection and gender in Russian. 
masculine, feminine and neuter, but the semantic effect of neuter, if anything, has to do with inanimacy, rather than gender in the non-technical sense of the term. There are also languages that are described as having gender categories like nonfresh food (see Corbett 2000 and references therein), which one might hesitate to call genders. Also, there are examples of morphologically related pairs of nouns that semantically differ along dimensions other than what one usually means by 'gender'. For example, in Spanish the feminine noun naranja means the orange fruit while its morphologically related masculine form naranjo means the orange tree. Similarly in Breton (Stump 2005) and Ojibwe (Mathieu 2012), gender marking on certain nouns shows interpretative effects that have to do with mass/count. Nonetheless, we will stick to the standard terminology here and call the relevant phenomenon gender.

Important for the present paper is the fact that there are many cases of gender agreement that arguably have no semantic correlate. For example, thalasa 'sea' in Greek is a feminine noun, but this gender specification has no semantic motivation. Such examples are not necessarily confined to inanimate nouns. For instance, nouns like aghori 'boy' and koritsi 'girl' in Greek trigger neuter agreement, but this gender marking has no semantic import. An extreme case of this is perhaps Modern Standard Dutch, where gender is only loosely, if at all, related to interpretation even in the domain of nouns describing humans and animals.

Thus, there are cases where gender seems to have some semantic effects and cases where it doesn't. In this paper we will call the former cases natural genders and the latter cases grammatical genders. ${ }^{2}$ The main concern of the present paper is the syntax and semantics of these two types of gender. In particular, we will closely examine properties of nouns that describe animals, or animal nouns, which have been largely neglected in the theoretical literature (limited discussion can be found in Corbett 1991; Comrie 1999; Bobaljik \& Zocca 2011; Yanovich 2012; Kramer 2015, for example). Taking Greek as a case study, we will argue that both natural gender and grammatical gender can be found among animal nouns, and to this extent they are similar to nouns that describe humans, or human nouns. However, we will observe several crucial differences between these two classes of nouns. To see this, we first need to introduce the idea of markedness.

\section{Markedness and Interpretation of Gendered Human Nouns}

Interpretation of gender on human nouns is a well discussed topic. In the case of Greek the vast majority of them have natural gender (Merchant 2014; Sudo \& Spathas to appear), and all cases of grammatical gender are neuter nouns, like a handful of idiosyncratic cases like (1), or nouns involving a diminutive suffix like -aki, which turns any noun into a neuter noun.

2. We should note that these terms might be used in different ways by different authors, as an anonymous reviewer pointed out to us. 
Previous studies, in particular Sudo \& Spathas (to appear) (see also Merchant 2014, Bobaljik \& Zocca 2011), have identified three ways in which natural gender manifests itself in the interpretation of human nouns. One is as a presupposition, another is as part of the assertion (and presumably simultaneously as part of the presupposition), and finally via competition with the other gender. The following examples illustrate their analysis. From now on, the gender (in the sense of agreement) of each noun is indicated by a subscript, and non-gender presuppositions (number, animacy, etc.) are simply ignored. ${ }^{3}$

(2) $\llbracket \operatorname{jatros}_{F} \rrbracket=\lambda x: x$ is female. $x$ is a doctor

(3) a. $\llbracket \operatorname{vasilias}_{M} \rrbracket=\lambda x: x$ is male. $x$ is male monarch

b. $\llbracket$ dhaskala $_{F} \rrbracket=\lambda x: x$ is female. $x$ is a female teacher

(4) a. $\llbracket \operatorname{jatros}_{M} \rrbracket=\lambda x . x$ is a doctor

b. 【dhaskalos ${ }_{M} \rrbracket=\lambda x . x$ is a teacher

Of particular interest here is the third kind like (4) that has no gender inference in the lexical semantics but gets one via competition with the feminine form. More concretely, according to this idea, (5a) is semantically consistent but is nonetheless infelicitous, because its feminine counterpart (5b) blocks it.
a. *I Maria ine dhaskalos. the Maria is teacher $_{M}$ 'Maria is a teacher.'
b. I Maria ine dhaskala. the Maria is teacher $F$ 'Maria is a female teacher.'

Sudo \& Spathas's analysis above is based on a number of linguistic tests. For instance, pluralization can be used to see if the lexical semantics involves natural gender: when a noun that has natural gender is pluralized, it describes uni-gendered groups, while a noun without natural gender is pluralized, it can describe mixedgendered groups. Concretely, vasiliadhes ${ }_{M}$ 'kings' only describes male-only groups and dhaskales $_{F}$ 'female teachers' only describes female-only groups, while dhaska$l i_{M}$ 'teachers' can be true of mixed-gendered groups as well as male-only groups, as shown by the following examples.

3. Recall that jatros, being an epicene noun, is compatible with both masculine and feminine agreement. We will write jatros $_{F}$ when this noun triggers feminine agreement and jatros ${ }_{M}$ when it triggers masculine agreement. As Sudo \& Spathas (to appear) stress, these denotations need not and should not be thought of as the denotations of the roots or the nouns themselves, but potentially of some larger constituent. We will adopt one concrete idea about this due to Spathas (2019), which will be introduced below. 
(6) a. \#O Petros ke i Maria ine $\operatorname{vasiliadhes}_{M}$. the Petros and the Maria are kings.M

b. \#O Petros ke i Maria ine dhaskales $_{F}$ stin Katerini. the Petros and the Maria are teachers.F in.the Katerini

(7) $\mathrm{O}$ Petros ke i Maria ine dhaskali ${ }_{M}$ stin Katerini. the Petros and the Maria are teachers.M in.the Katerini 'Petros and Maria are teachers in Katerini.'

Note that dhaskali $_{M}$ cannot describe female-only groups. This is in line with Sudo \& Spathas's (to appear) analysis, according to which the feminine plural form dhaskales $_{F}$, which only describes female-only group, renders dhaskali ${ }_{M}$ infelicitous in such a case.

Negative existential sentences like (8) show essentially the same thing. Concretely, the masculine noun dhaskalos ${ }_{M}$ 'teacher' behaves as if it is genderneutral in (8a), while the feminine noun dhaskala ${ }_{F}$ 'female teacher' retains its gender inference in (8b). Consequently, (8a) has a stronger meaning than (8b).

(8) a. O Petros dhen exi dhaskalo ${ }_{M}$ stin Katerini. the Petros not has teacher.M in.the Katerini 'Petros doesn't have a teacher in Katerini.'

$\Rightarrow$ Petros doesn't have a female teacher in Katerini

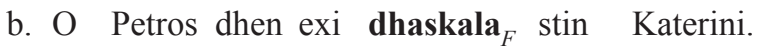
the Petros not has teacher.F in.the Katerini 'Petros doesn't have a female teacher in Katerini.'

$\nRightarrow$ Petros doesn't have a male teacher in Katerini

Masculine nouns with lexically specified gender like vasilias $_{M}$ also keep their gender inference in this construction, just like (8b), as shown in (9).

(9) I Agglia dhen exi vasilia $_{M}$ the England not has $\operatorname{king}_{M}$ 'England doesn't have a king.'

$\nRightarrow$ England doesn't have a queen

In addition to these two diagnostics for the presence of natural gender in the denotation, Sudo \& Spathas (to appear) make use of focus constructions to see if the natural gender in the denotation is asserted or merely presupposed. They observe that in focus constructions, nouns like jatros ${ }_{F}$ that only presuppose gender and nouns like dhaskala that also assert gender behave differently, as illustrated by (10). 
(10) a. Mono i Maria ine kali jatros $_{F}$. only the Maria is good.F doctor 'Only Maria is a good doctor.'

$\Rightarrow$ Petros is not a good doctor.

b. Mono i Maria ine kali dhaskala ${ }_{F}$. only the Maria is good.F teacher.F 'Only Maria is a good teacher.' $\quad \nRightarrow$ Petros is not a good teacher.

Similar effects are observed with other focus constructions like superlatives and nominal ellipsis, although as Sudo \& Spathas (to appear) remark, judgments about nominal ellipsis seem to be relatively unstable in Greek.

Sudo \& Spathas's analysis above reveals some generalizations that hold among human nouns in Greek. Firstly, there is no masculine noun where the gender inference is only presupposed, and there is no feminine noun that is lexically underspecified for gender. Thus, masculine human nouns either have asserted (as well as presupposed) gender, as in the case of vasilias ${ }_{M}$ 'king', or have no lexically specified gender, as in the case of dhaskalos ${ }_{M}$ 'teacher'. On the other hand, feminine nouns always have natural gender inference in their semantics, more specifically, either as part of the presupposition, as in the case of jatros ${ }_{F}$ 'doctor', or as part of the asserted meaning (as well as part of the presupposition), as in the case of dhaskala ${ }_{F}$ 'female teacher'. In addition, there is no masculine-feminine pair in which the masculine noun has asserted gender, while the feminine noun does not. This is summarized in (11).

(11) Generalizations about human nouns in Greek

a. Masculine

(i) Asserted (and presupposed) gender (e.g. vasilias $_{M}$ 'king')

(ii) No gender inference in the semantics; shows blocking effects with respect to the feminine counterpart (e.g. jatros $_{M}$ 'doctor', dhaskalos ${ }_{M}$ 'teacher')

b. Feminine

(i) Asserted (and presupposed) gender (e.g. dhaskala ' 'female teacher')

(ii) Only presupposed gender (e.g. jatros ${ }_{F}$ 'doctor')

c. Impossible cases

(i) Masculine with only presupposed gender

(ii) Feminine that has no gender inference in the semantics but shows blocking effects

These observations relate to the idea of markedness (Jakobson 1984). In European languages with nominal gender systems, masculine is generally said to be less marked than feminine in the sense that masculine nouns can be lexically underspecified for gender and used as elsewhere cases, while feminine nouns tend to have gender inferences (e.g. Sauerland 2008; Bobaljik \& Zocca 2011; Percus 2011; Kiparsky \& Tonhauser 2012). ${ }^{4}$ Although not free of exceptions, this has led some

4. The literature often also discusses morphological markedness, in addition to the semantic notion of markedness. That is, in languages like Russian, the masculine form is usually simpler than the 
researchers to assume that the masculine feature, at least in most cases, has trivial semantics and has no entailments about gender (Percus 2011; see also Sauerland 2003; Heim 2008; Sauerland 2008 for the same point about pronominal gender). ${ }^{5}$ Sudo \& Spathas's (to appear) analysis is a version of this, except that they admit masculine nouns that have asserted gender in the semantics, like vasilias $_{M}$ 'king').

Note that Sudo \& Spathas (to appear) are vague about whether or not these 'nouns' are further decomposable into smaller morphosyntactic elements. In fact, what they call nouns can well be bigger than what might be called NP or $n \mathrm{P}$ in the current syntactic literature. Building on Sudo \& Spathas (to appear), Spathas (2019) makes a more precise proposal about the ways in which the structural properties of these 'nouns' correlate with their semantics. This idea is particularly useful in the following discussion, so let us delve into it.

Spathas proposes that nouns with asserted genders like vasilias $_{M}$ 'king' and dhaskala $_{F}$ 'female teacher' carry gender inferences at a very low level in the structure, perhaps at the root level. These cases can be thought of as lexicalizations of concepts that inherently carry gender inferences.

(12) a. $\|\sqrt{\text { vasilias }}\|=\lambda x . x$ is male and $x$ is a monarch

b. $\llbracket \sqrt{\text { dhaskala }} \rrbracket=\lambda x . x$ is female and $x$ is a teacher

On the other hand, nouns without asserted gender, e.g. jatros 'doctor' and dhaskalos 'teacher', have nominal roots with gender-neutral semantics.

(13) a
a. $\llbracket \sqrt{\text { jatros }} \|=\lambda x . x$ is a doctor
b. $\llbracket \sqrt{\text { dhaskalos }} \rrbracket=\lambda x . x$ is a teacher

Following Kramer (2014), Spathas (2019) furthermore assumes that these roots combine with $n$, which can be seen as the locus of syntactic agreement. Crucially, Spathas proposes that $n$ can introduce one of two gender-related presuppositions for nouns with natural gender. Specifically, nouns that agree in feminine combine with $n_{F}$, which presupposes femaleness, and nouns that agree in masculine

feminine form, e.g. uchitel' $_{M}$ vs. uchitel'nica ${ }_{F}$ 'teacher'. However, morphological markedness does not straightforwardly apply to Greek, because in most cases of morphologically related pairs of gendered nouns, both masculine and feminine forms bear some suffix, as in dhaskal-os vs. dhaska-la $a_{F}$, and it is not obvious which suffix is less marked. We put aside the issue of morphological markedness in the present paper.

5. According to Murphy, Puškar \& Naranjo (2018), Puškar (2017, 2018), epicene nouns in Bosnian/ Croatian/Serbian show the opposite pattern, i.e. the feminine feature seems to be uninterpreted, while the masculine feature triggers a gender entailment. An anonymous reviewer mentions a similar case in Polish, straszna ${ }_{F}$-straszny ${ }_{M}$ 'butterfingers', although it seems to us that these cases are more similar in nature to animal nouns in that these gender-neutral nouns do not give rise to blocking effects. The same reviewer also mentions widow vs. widower but the relevant markedness here is morphological and at the semantic level both these nouns involve asserted genders, so they are similar to king vs. queen. As mentioned in the previous footnote, we do not have much to say about morphological markedness in this paper. 
combine with $n_{M}$, which presupposes no gender. Here, the term 'masculine' is misleading, because it actually does not mean masculine.

(14) a. $\llbracket n_{M} \rrbracket=\lambda P . \lambda x . P(x)$

b. $\llbracket n_{F} \rrbracket \quad=\lambda P . \lambda x: x$ is female. $P(x)$

Crucially, there is no $n$ that introduces a maleness presupposition in Greek, and this corresponds to the aforementioned idea of unmarked masculine (although, as mentioned in fn. 5 , such a version of $n$ might be necessary for other languages). It is also assumed that whenever possible, (14b) must be chosen, which captures the blocking effects mentioned earlier (see Sudo \& Spathas to appear for a concrete implementation of how this competition works; these details are unnecessary for the purposes of this paper).

A couple of caveats are in order. Firstly, what is called a 'root' need not be syntactically simple or correspond transparently to a morphological root. In principle, a root could be made up of several smaller syntactic units (which might be roots themselves). Also, we do not need to make particular assumptions about the morphological properties of roots and $n$ 's. That said, if a root is further decomposable, we might be able to capture morphological similarities more straightforwardly. For example, the morphological resemblance of dhaskala ${ }_{F}$ 'female teacher' and dhaskalos $_{M}$ 'teacher' suggests that they do have some common syntactic core. In our analysis above, however, they are analyzed as involving different roots. One potential way to reconcile them is by assuming that the root for the former feminine noun is made up of the root for the latter masculine noun and some other component, perhaps also a root, that introduces the femaleness entailment in the assertive meaning. We do not see conclusive evidence for or against this idea at the moment. In particular, nothing in the morphology of these nouns seems to correspond to such an extra component in the root. For this reason, we leave this as an analytical option for now, but we will come back to this point after discussing the data of animal nouns.

Secondly, we have said nothing so far about how grammatical gender works. In the current syntactic literature there are several proposals about the syntactic properties of natural vs. grammatical gender (cf. Kramer 2014; Landau 2016; Matushansky 2013; Murphy et al. 2018; Pesetsky 2013; Puškar 2017, 2018), and this question will become particularly important later on, so we will reserve the discussion until then. However, at this point it should be stressed that none of these previous studies make a distinction between asserted vs. presupposed gender, and their proposals should be understood as about presupposed gender. Spathas's (2019) main claim is that asserted genders should be represented very low in the nominal structure, as part of, or at least very close to, the root and that the only grammatically relevant gender (in the sense that it participates in agreement dependencies) is the gender on $n$ (In this sense, a gender on $n$ that carries gender inferences is both 'natural' and 'grammatical').

Let us now summarize the key facts about human nouns in Greek. Firstly, there are human nouns with grammatical gender (e.g. neuter nouns like koritsi 'girl') and human nouns with natural gender. Among human nouns with natural gender, the 
ones that can agree in masculine or feminine are called epicene nouns (e.g. jatros 'doctor'). According to Sudo \& Spathas (to appear), masculine epicene nouns have no gender inferences, while feminine epicene nouns only presuppose gender in Greek. In Spathas's (2019) theory, this means that epicene nouns all have roots that are lexically unspecified for gender, and a gender presupposition is introduced by $n_{F}$. The other flavor of $n$, namely $n_{M}$, does not trigger a gender presupposition, but is subject to the blocking effect such that whenever $n_{F}$ can be used to mean the same thing, it must.

$$
\llbracket \sqrt{\text { jatros }} \rrbracket=\lambda x . x \text { is a doctor }
$$

Nouns like vasilias ${ }_{M}$ 'king' and vasilissa 'queen', on the other hand, both have asserted gender, so under Spathas's (2019) view, they have roots with lexically specified genders.

(16) a. $\llbracket \sqrt{\text { vasilias }} \|=\lambda x . x$ is male and $x$ is a monarch

b. $\llbracket \sqrt{\text { vasilissa }} \rrbracket=\lambda x . x$ is female and $x$ is a monarch

Lastly, there are pairs like dhaskalos ${ }_{M}$ 'teacher' vs. dhaskala 'teacher' where the masculine form has no gender, but the feminine form involves asserted gender.

(17) a. $\llbracket \sqrt{\text { dhaskalos }} \rrbracket=\lambda x \cdot x$ is a teacher

b. $\llbracket \sqrt{\text { dhaskala }} \rrbracket=\lambda x . x$ is female and $x$ is a teacher

As in the case of jatros, the feminine form must be used whenever possible. The following generalizations hold among human nouns with natural gender.

(18) a. Masculine human nouns either assert (and presuppose) gender, or are gender neutral.

b. Feminine human nouns either assert (and presuppose) gender, or presuppose gender.

c. For any masculine-feminine pair of human nouns, if the masculine noun asserts gender, then so does the feminine noun.

The idea that masculine is semantically less marked than feminine in languages like Greek and has gender-neutral semantics is widely countenanced, and in the domain of human nouns, this idea seems to be exceptionless. ${ }^{6}$ However,

6. As mentioned above, there are human nouns with grammatical gender, e.g. neuter nouns like aghori 'boy' in Greek, feminine nouns like persona 'person' in Spanish and Russian. The claim here is that there is no pair of feminine-masculine nouns where the feminine is semantically less marked, at least in Greek. However, the facts noted in fn.5 show that this is not an absolute universal, even among European languages. See also Corbett (1991), Kramer (2015) for languages where feminine is generally less marked. 
very little has been said in the theoretical literature about examples found in the domain of animal nouns that are seemingly problematic for this idea. Concretely, ghata 'cat' in Greek is a feminine noun with respect to agreement, but semantically it is used to described a cat of any gender, while its masculine counterpart, ghatos, is used to only describe a male cat. How could we maintain the semantic unmarkedness of masculine that seems to nicely hold in the domain of human nouns in light of such examples? This is the question we would like to address in the rest of this paper.

\section{Animal Nouns}

There are three sub-classes of animal nouns, depending on which gender is the 'default' gender, by which we mean the gender (with respect to agreement) that is not associated with a gender- related interpretation. In this section we will discuss these three sub-classes in turn.

\subsection{Neuter-Default Nouns}

As in the case of human nouns, there are animal nouns that arguably have grammatical gender. For example kuneli ${ }_{N}$ 'rabbit' is a neuter noun and can describe rabbits of either sex. Here is a list of neuter animal nouns in Greek.

$\begin{array}{llllll}\text { (19) } \begin{array}{l}\text { kuneli } \\ \text { pouli }\end{array} & \text { 'rabbit' } & \text { pontiki } & \text { 'mouse' } & \text { alojo } & \text { 'horse' } \\ \text { puladi } & \text { 'foal' } & \text { koraki } & \text { 'crow' } & \text { vodhi } & \text { 'ox' } \\ \text { liontari } & \text { 'lion' } & \text { elafi } & \text { 'octopus' } & \text { fidhi } & \text { 'snake' } \\ \text { arni } & \text { 'lamb' } & \text { jeraki } & \text { 'hawk' } & \text { provato 'sheep' } & \\ \end{array}$

All of these nouns are semantically underspecified for gender, except for vodhi 'ox'. In addition, there are neuter animal nouns that contain the highly productive diminutive suffix - aki, which renders any noun neuter. In this case too, the neuter gender arguably has no semantic correlate.

Interestingly some of these neuter animal nouns have gendered variants, e.g. kunela 'female rabbit', puladha 'filly', leena 'lioness', foradha 'mare' (most other nouns can form a feminine version restricted to females by use of the derivational suffix -ina). For example, kuneli ' $^{\text {'rabbit' has a feminine form kunela }}$ 'female rabbit', which has a gender inference, as evidenced by the fact that its plural form kuneles $_{F}$ means 'female rabbits' and is incompatible with a group containing a male rabbit. Also, in a negative existential sentence, kunela retains its gender inference.

(20) I Marie dhen kratai kamia kunela ${ }_{F}$ ston kipo. the Maria not keeps no.F rabbit.F in.the garden 'Maria keeps no female rabbit in the garden.'

$\nRightarrow$ Maria keeps no male rabbit in the garden 
Furthermore, (21) shows that the gender inference is observed in focus constructions, which indicates that kunela $_{F}$ 'female rabbit' asserts (and presupposes) gender.

(21) Mono i Judy ine kunela ${ }_{F}$ only the Judy is rabbit.F 'Only Judy is a female rabbit.'

$\nRightarrow$ Stu is not a male rabbit

Similar observations can be made with other feminine variants of the above nouns, including feminine nouns formed with the suffix -ina.

(22) Mono i Judy ine puladha ${ }_{F}$. only the Judy is filly.F

'Only Judy is a filly.'

$\nRightarrow$ Stu is not a colt

(23) Mono i Judy ine jerakina ${ }_{F}$. only the Judy is hawk.F 'Only Judy is a female hawk.'

$\nRightarrow$ Stu is not a male hawk

The suffix -ina is quite productive in the domain of animal nouns, and seems to always result in an asserted feminine gender.

As in the case of human nouns, neuter-default animal nouns like kuneli ${ }_{N}$ can be understood as involving grammatical gender, but importantly there does not seem to be a neuter human noun that has a morphologically related feminine form with a gender inference. Thus, pairs like kuneli $_{N}-$ kunela $_{F}$ can only be found among animal nouns.

It is also worth noting that some of the nouns in the above list have morphologically related masculine forms, but none of these masculine forms have gender inferences. For example, pontiki ${ }_{N}$ 'mouse' has a morphologically related masculine form pontikos $_{M}$, but this noun is also gender neutral (however, as we discuss in the next section, it can also have a reading with an asserted gender). Another such case is koraki $_{N}$ 'crow', whose masculine form is korakas $_{M}$, but its meaning is 'raven', rather than 'male crow'. Again, there do not seem to be such cases of neuter-masculine pairs in the domain of human nouns where the masculine variant has no gender inference but some other idiosyncratic meaning.

\subsection{Masculine-Default Animal Nouns}

Among masculine animal nouns, one can certainly find cases that are at least compatible with the hypothesis that the gender is interpreted, e.g. $\operatorname{traghos}_{M}$ 'male goat' and ghatos 'male cat'. At the same time, it is not hard to find masculine animal nouns that don't have gender inferences. Here are some examples of the latter kind. 


\begin{tabular}{|c|c|c|c|c|c|}
\hline (24) skilos & 'dog' & elefantas & 'elephant' & likos & 'wolf' \\
\hline laghos & 'hare' & pelekanos & 'pelican' & aetos & 'eagle' \\
\hline korakas & 'raven' & tavros & 'bull' & jaidharos & 'donkey' \\
\hline arureos & 'rat' & skiuros & 'squirrel' & karxarias & 'shark' \\
\hline vatraxos & 'frog' & pithikos & 'monkey' & tarandhos & 'elk' \\
\hline
\end{tabular}

A couple of these have morphologically related feminine forms. For instance, while the masculine form skilos ${ }_{M}$ is the default in the sense that this form of the noun can describe a dog of either sex, there is a feminine form skila ${ }_{F}$, which means 'female dog' (also used idiomatically as a slur against women). The same diagnostics as above indicate that this noun asserts gender. Firstly, observe that in a negative existential sentence, the gender inference of skila $_{F}$ is specified lexically.

(25) I Marie dhen kratai kamia skila ${ }_{F}$ ston kipo. the Maria not keeps no.F dog.F in.the garden 'Maria keeps no female dog in the garden.'

$\nRightarrow$ Maria keeps no male dog in the garden

Furthermore, the following example with a focus construction indicates that the gender is asserted.

(26) Mono i Ellie ine skila only the Ellie is dog.F

'Only Ellie is a female dog.'

$\nRightarrow$ Brian is not a male dog

In addition, there is also a neuter form $s k i l i_{N}$, which is gender neutral (and also figuratively means 'hard worker'). We are not aware of such a triplet of morphologically related human nouns in Greek.

Other animal nouns in (25) that have morphologically related feminine forms are, likos $_{M}$ 'wolf', whose feminine form is likena ${ }_{F}$ 'female wolf', and laghos 'hare', whose feminine form is lajina ${ }_{F}$ 'female hare'. Similarly for skiuros 'squirrel' and skiurina 'female squirrel'. These feminine forms can be shown to assert gender. Concretely, observe the following entailment properties (note that these cases involve the suffix -ina, potentially except for likena $a_{F}$ ).

(27) Mono i Ellie ine likena ${ }_{F}$

only the Ellie is wolf.F

'Only Ellie is a female wolf.'

$\nRightarrow$ Brian is not a male wolf

(28) Mono i Ellie ine skiurina ${ }_{F}$. only the Ellie is squirrel.F

'Only Ellie is a female squirrel.'

$\nRightarrow$ Brian is not a male squirrel

One notable difference between human nouns and animal nouns is that none of the above animal nouns exhibit blocking effects, even when there is a morphologi- 
cally related feminine form. Thus, skilos 'dog' can perfectly felicitously describe a single female dog, as shown by examples like the following.

(29) I Ellie ine skilos $_{M}$. the Ellie is dog.M

'Ellie is a dog.'

(30) Exo enan skilo. Ine egkios.

have.1SG a.M dog.M is.3SG pregnant

'I have a dog. She is pregnant.'

This is unlike a human noun such as dhaskalos ${ }_{M}$ 'teacher', which according to Sudo \& Spathas (to appear) is semantically compatible with a single female teacher, but cannot be used to describe her due to the blocking effect.

\subsection{Feminine-Default Animal Nouns}

There are some feminine animal nouns that arguably have natural gender inferences, e.g. jidha, ega, and katsika, which all mean 'female goat'. At the same time, some feminine animal nouns have no gender inferences such as the following.

$\begin{array}{llllll}\text { (31) ghata } & \text { 'cat' } & \text { alepou 'fox' } & \text { kota } & \text { 'chicken } \\ \text { xelona } & \text { 'turtle' } & \text { papia 'duck' } & \text { kamila 'camel' } \\ \text { kamilopardhali } & \text { 'giraffe' } & \text { araxni 'spider' } & \text { arkudha 'bear' } \\ \text { ajeladha } & \text { 'cow' } & \text { kukuvaja 'owl' } & \text { ghlavka 'owl' } \\ \text { tighri } & \text { 'tiger' } & & & & \end{array}$

That these feminine nouns have gender-neutral semantics is illustrated by the following entailment patterns for ghata $_{F}$.

(32) Dhen afino kamia ghata ${ }_{F}$ mesa sto spiti. not leave no.F cat.F inside in.the house

I allow no cat in the house.' $\quad \Rightarrow$ I allow no male cat in the house

(33) Apo ta katikidhia mu, mono i Ellie ine ghata ${ }_{F}$. from the pets my, only the Ellie is cat.F

'Among my pets, only Ellie is a cat.'

As remarked in the previous section, nouns like (31) are never found in the domain of human nouns in Greek. The noun ghata $_{F}$ 'cat' is of particular interest here, because it has a morphologically related masculine form ghatos ${ }_{M}$ 'male cat', which has a gender inference. Similarly for arkudha ${ }_{F}$-arkudhos ${ }_{M}$ 'bear'. Relevant data indicate that the gender of these masculine variants is asserted. Firstly, in a negative existential sentence, there is no entailment to the opposite gender. 
(34) I Maria den exi ghato $_{M}$. the Maria not has cat.M 'Maria does not have a male cat.' $\quad \Rightarrow$ Maria does not have a female cat

Furthermore, the following example shows that this gender inference is asserted.

(35) Mono o Garfield ine ghatos ${ }_{M}$. only the Garfield is cat.M

'Only Garfield is a male cat.'

$\nRightarrow$ Arlene is not a female cat

In addition, there is a neuter form, jati $i_{N}$, which means 'kitten'.

As in the case of masculine-default animal nouns, the default feminine forms in (31) can felicitously apply to male animals without exhibiting blocking effects, even when there is a morphologically related masculine form. Thus, the following examples are perfectly acceptable.

(36) $\mathrm{O}$ Garfield ine jata . $_{\text {. }}$

the Garfield is cat.F

'Garfield is a cat.'

(37) Exo mia jata. Ton lene Roger.

have.1SG a.F cat.F. him call.3PL Roger

'I have a cat. He is called Roger.'

\section{Towards an Analysis}

To sum up the key observations, there are several properties of animal nouns that distinguish them from human nouns. Firstly, any of the three genders can be semantically neutral in the domain of animal nouns, and in each case one can find examples that have a morphologically related form with natural gender. Relevant examples are: kuneli $N^{-}$kunela $_{F}$ 'rabbit', skilos ${ }_{M^{-}}$skila $_{F}$ 'dog', and ghata ${ }_{F}$ -ghatos ${ }_{M}$ 'cat', where the first member of each pair is semantically gender neutral. In the domain of human nouns in Greek, only masculine can be gender neutral, if there is a morphologically related feminine form, and such a gender neutral masculine human noun always exhibits blocking effects. It appears that no animal nouns show blocking effects even when there are morphologically related forms with natural gender.

In addition, in the case of animal nouns, all cases of natural gender seem to involve asserted gender. In other words, there is no case like jatros ${ }_{F}$ 'doctor', where the gender is only presupposed, and all cases of natural gender are similar in quality to vasilias $_{M}$ 'king' and dhaskala ' 'female teacher'.

How do these observations square with the idea that masculine in Greek is unmarked? Here is one way to make sense of the data within the theoretical view introduced earlier. 
- All gender-neutral animal nouns involve grammatical genders. There are no gender-neutral roots for animal nouns that are similar in nature to human nouns like dhaskalos ${ }_{M}$ 'teacher' and jatros 'doctor' and have gendered variants that trigger blocking effects.

- Natural genders of animal nouns are always asserted. There is no noun like jatros $_{F}$ 'doctor' that only presupposes gender. Relatedly, there is no epicene nouns among animal nouns that can agree in feminine or masculine.

In what follows, we will discuss the above two points in more detail, but before moving on, we would like to raise one additional piece of support for the former point using nominal ellipsis with gender mismatches. As observed by Merchant (2014) and Sudo \& Spathas (to appear), nouns like dhaskalos ${ }_{M}$ 'teacher' license gender mismatching nominal ellipsis, as in (38). ${ }^{7}$

(38) O Petros episkefthike enan dhaskalo ${ }_{M}$ stin Veria, ke mia the Petros visited a.M teacher.M in.the Veria and one.F stin Katerini. in.the Katerini

'Petros visited a male teacher in Veria, and a female teacher in Katerini.'

In contrast, grammatical gender never licenses such gender mismatching ellipsis, as shown in (39).

(39) $*$ O Petros episkefthike ena koritsi ${ }_{N}$ stin Veria, ke mia __stin the Petros visited a.N girl.N in.the Veria and one.F in.the Katerini.

Katerini

'(intended) Petros visited a girl in Veria, and one in Katerini.'

We observe that the relevant gender neutral animal nouns behave like (39).

(40) $*$ O Petros kratai ena kuneli $i_{N}$ ston kipo tou, kai mia/enan ___ mesa the Peter keeps a.F rabbit.N in.the garden his, and a.F/a.M inside sto spiti.

in.the house

'(intended) Peter keeps a rabbit in his garden, and a male/female rabbit inside the house.'

7. Sudo \& Spathas (to appear) report that the judgments of examples like (38) are not as clear as with nouns like jatros 'doctor' or with gender-matching ellipsis, but they are certainly better than cases like the following.

(i) ${ }^{*} \mathrm{O}$ Petros episkefthike enan adherfo $_{M}$ tu stin Veria, ke episkefthike mia ___ stin the Petros visited a.M brother his in.the Veria and visited one.F in.the Katerini.

Katerini

(intended) 'Petros visited a brother of his in Veria, and he visited a sister in Katerini.' 
(41) *O Petros kratai enan skilo $_{M}$ ston kipo tou, kai mia __ mesa the Peter keeps a.m cat.M in.the garden his, and a.F inside sto spiti.

in.the house

'(intended) Peter keeps a dog in his garden, and a female dog inside the house.'

(42) *O Petros kratai mia ghata ${ }_{F}$ ston kipo tou, kai enan ___ mesa the Peter keeps a.F cat.F in.the garden his, and a.m inside sto spiti.

in.the house

'(intended) Peter keeps a cat in his garden, and a male cat inside the house.'

\subsection{Grammatical Gender}

To be more concrete with these ideas, we have to make some assumptions about how grammatical gender is represented syntactically, and there are a few analytical possibilities. One possibility is that grammatical genders are versions of $n$ on a par with other flavors of $n$, except that $n$ with grammatical genders have no semantic content (cf. Kramer 2014; Spathas 2019). Under this view it is reasonable to assume that certain stems are required to combine with a particular type of $n$ with grammatical gender, including bona fide cases of grammatical gender like kipos 'garden' and $a v l i_{F}$ 'backyard'. Then, the gender neutral nouns like kuneli $i_{N}$ 'rabbit', skilos $_{M}$ ' $\operatorname{dog}^{\prime}$ ', and ghata $_{F}$ 'cat' combine with $n$ with a grammatical gender. We can assume the same thing for animal nouns that do not have related forms with natural genders, e.g. fidhi 'snake', karxarias $_{M}$ 'shark', araxni ${ }_{F}$ 'spider'.

Alternatively, we could assume that grammatical genders are syntactically represented in a different way from presupposed natural genders, which we have been assuming are encoded in $n$. There are two possibilities here with respect to which of natural and grammatical gender is structurally higher. Puškar $(2017,2018)$ proposes that grammatical gender is introduced above $n$, while Matushansky (2013), Pesetsky (2013) and Landau (2016) propose that grammatical gender is lower than the locus of presupposed natural gender. The core arguments for these analyses come from data involving DP-internal agreement mismatch, but in Greek such agreement mismatches are generally unacceptable. Therefore as far as this language is concerned, there is no evidence for or against either of these views. In fact, in the absence of DP-internal agreement mismatch, there isn't even direct evidence for assigning different syntactic positions for grammatical and (presupposed) natural gender. ${ }^{8}$ Thus we think all these theoretical possibilities are compatible with our analysis here.

There is however some conceptual arguments for or against some of these ideas. In particular, given our observations above, it is crucial for us to assume that nouns with grammatical gender do not trigger blocking effects with nouns

8. See Spathas (2019) for arguments based on patterns of presupposition projection and the distribution of exceptive phrases that presupposed natural gender is lower than D (contra Sauerland 2003, 2008). 
with natural gender, no matter what the morphological properties of the relevant nouns are. Under the view where both natural and grammatical gender are versions of $n$, this amounts to assuming that $n$ bearing natural gender does not compete with $n$ bearing grammatical gender. On the other hand, if natural and grammatical gender have different syntactic properties, this assumption might fall out more naturally. That is, it has been suggested that blocking effects and other interpretive effects that arise in reference to alternative expressions (e.g. focus, scalar implicatures, and anti-presuppositions) are constrained by certain structural considerations (cf. Katzir 2007). It does not seem to us to be too farfetched to assume that for gender-related blocking effects, the expressions to be compared need to be structurally isomorphic. If grammatical and natural genders involve different types of heads, then no blocking effects are predicted between them. This might therefore favor an analysis that encodes grammatical and natural gender differently, but whether or not such a structural constraint is feasible in the general case needs to be assessed against a general theory of alternatives, which goes far beyond the scope of the present paper (see Breheny, Klinedinst, Romoli \& Sudo 2018 for relevant discussion), so the argument here is not very conclusive.

\subsection{Natural Gender}

Besides animal nouns with grammatical gender, we also observed many examples with natural genders. One peculiarity here is that such examples all involve asserted gender. In Spathas's (2019) terms, this means that they all lexicalize gendered concepts. More concretely, the roots of the relevant nouns all carry gender inferences and hence look like (43).

(43) a. $\llbracket \sqrt{\text { kounela }} \rrbracket=\lambda x \cdot x$ is female and $x$ is a rabbit

b. $\llbracket \sqrt{\text { skila }} \rrbracket=\lambda x . x$ is female and $x$ is a dog

c. $\llbracket \sqrt{\text { jatos }} \rrbracket=\lambda x . x$ is male and $x$ is a cat

It must be ensured that these roots combine with the correct type of $n$, but we can assume that the mechanism is the same as in the case of human nouns.

At this point, we would like to come back to the idea mentioned in Section 2 that roots could be complex. This is merely a theoretical possibility, but if it is viable, it will allow us to have a nice analysis of the suffix -ina. As we observed in the previous section, this suffix always adds an asserted feminine inference. In our model based on Spathas (2019), this asserted gender should be contained in the root. To make sense of this, we could assume that -ina combines with a root and produces a complex root whose semantics is the (generalized) conjunction of the meaning of the original root and asserted feminine gender, as illustrated by (44).

(44) a. $\llbracket \sqrt{\text { jeraki } \rrbracket}=\lambda x . x$ is a hawk

b. $\llbracket \sqrt{\text { jeraki }+ \text { ina }} \rrbracket=\lambda x . x$ is a hawk and $x$ is female 
All animal nouns with natural gender can be analyzed analogously, which we think is a nice result. At the same time, this is not enough, since we also made generalizations about the non-existence of certain types of nouns and we would like to understand why they don't exist. Specifically, there are no animal nouns that only presuppose gender, which would be similar to human nouns like jatros ${ }_{F}$ 'doctor'. There are also no animal nouns that have vacuous natural gender and are subject to blocking effects, which would be similar to human nouns like jatros ${ }_{M}$ 'doctor' and dhaskalos ${ }_{M}$ 'teacher'. Or to put it conversely, one can find gender-neutral roots that can combine with natural gender $n$ only among human nouns. Gender-neutral roots for animal nouns all combine with grammatical gender. Of course we want to account for these restrictions in principle ways, but we have to admit that we are unable to offer a concrete account at this moment. Nonetheless, we would like to mention some speculations and conjectures below.

\subsection{Some Further Thoughts}

Both for human and animal nouns, masculine and feminine ones that have genderneutral uses also seem to have gendered uses. This was actually mentioned by Jakobson (1984), whose work the very idea of markedness originally comes from. He illustrates markedness in the domain of gender with an animal noun in Russian in the following passage.

The Russian word oslica 'she-ass' indicates the female sex of the animal, whereas the general meaning of the word osël 'donkey' contains no indication of the sex of the animal in question. (Jakobson 1984: p. 1f)

We certainly hope that our analysis will be applicable to animal nouns in Russian and other languages with nominal gender. That is, we expect that gender neutral animal nouns like $o s l_{M}$ involve grammatical gender, while ones with natural gender like oslica $a_{F}$ assert gender, but we have to leave a detailed empirical investigation of Russian animal nouns for another occasion. What is important here is Jakobson's following observation made right after the passage quoted above.

If I say osël, I make no decision as to whether I have to do with a male or a female, but if I am asked èto oslíca? 'is it a she-ass?' and I answer nét, osël 'no, a donkey', then in this case the masculine gender is indicated - the word is used in a restricted sense.

Similar examples can be constructed in Greek. For example, recall that skilos $_{M}$ 'dog' is a masculine noun that can be used to describe female dogs as well. Similarly, ghata ${ }_{F}$ 'cat' is a feminine noun that can be used to describe male cats. In the following dialogues, however, they must be interpreted as non-gender neutral. 
(45) a. Ine skila? -Oxi, ine skilos. is.3SG dog.F no is.3SG dog.M 'Is it a female dog? — No, it is a male dog.'

b. Ine ghatos?-Oxi, ine ghata. is. $3 \mathrm{SG}$ cat.M no is. $3 \mathrm{SG}$ cat. $\mathrm{F}$ 'Is it a male cat? — No, it is a female cat.'

Neuter default nouns do not allow such an interpretation. For instance, $k u n e l i_{N}$ 'rabbit' is unacceptable in the following dialogue.

(46) Ine kunela? \#Oxi, ine kuneli. is.3SG rabbit.F no is.3SG rabbit.N (intended) 'Is it a female rabbit? —No, it is a male rabbit.'

The same point can be made with data involving conjunction and disjunction. Generally, conjunctions and disjunctions are usually infelicitous (at least very marked) when one conjunct/disjunct entails the other. For example:

(47) a. \#Exi enan skilo i ena zoo. has.3SG one.M dog.M or one.N animal '\#He has one dog or one animal.'

b. ??Exi enan skilo ke ena zoo. has.3SG one.M dog.M and one.N animal '??He has one dog and one animal.'

Compared to these sentences, the following are strikingly acceptable.

(48) a. Exi mia skila i enan skilo. has.3SG one.F dog.F or one.M dog.M 'He has one female dog or one male dog.'

b. Exi mia skila ke enan skilo. has.3SG one.F dog.F and one.M dog.M 'He has one female dog and one male dog.'

(49) a. Exi enan gato i mia gata. has.3SG one.M cat.M or one.F dog.F 'He has one male cat or one female cat.'

b. Exi enan gato ke mia gata. has.3SG one.M cat.M and one.F dog.F 'He has one male cat and one female cat.'

Again, a neuter gender-neutral noun does not allow this. 
(50) a. \#Exi mia kunela $\mathrm{i}$ ena kuneli. has.3SG one.F rabbit.F or one.N rabbit.F '\#He has one female rabbit or one rabbit.'

b. ??Exi mia kunela ke ena kuneli. has.3SG one.F rabbit.F and one.F rabbit.F '\#He has one female rabbit and one rabbit.'

These data suggest that those animal roots that have gender-neutral semantics and combine with grammatical masculine or feminine gender also have a version with an asserted gender (which presumably combines with a natural gender $n$ ).

It should be noted that the same thing can be observed with human nouns like dhaskalos $_{M}$ 'teacher'. Following Sudo \& Spathas (to appear) we have been assuming that this noun has a gender-neutral semantics, but in the following examples, it must be used as having a gender entailment.

(51) Exis kali dhaskala? -Oxi, exo kalo dhaskalo. have.2SG good.F teacher.F no, have.1SG good.M teacher.M

'Do you have a good female teacher? —No, I have a good male teacher.'

(52) a. Exi mia dhaskala i enan dhaskalo.

has.3SG one.F teacher.F or one.M teacher.m

'He has one female teacher or one male teacher.'

b. Exi mia dhaskala ke enan dhaskalo.

has.3sG one.F teacher.F and one.m teacher.m

'He has one female teacher and one male teacher.'

Importantly, epicene nouns do not behave like this.

(53) ??Exis kali jatro? -Oxi, exo kalo jatro.

have.2SG good.F doctor no, have.1SG good.M doctor

'(intended) Do you have a good female doctor? — No, I have a good male doctor.'

(54) a. ??Exi mia jatro i enan jatro.

has.3SG one.F doctor or one.M doctor

'He has one female doctor or one male doctor.'

b. ??Exi mia jatro ke enan jatro.

has.3SG one.F doctor and one.M doctor

'He has one female doctor and one male doctor.'

These observations suggest that epicene nouns are genuinely gender-neutral and their gender inferences just come from natural gender $n$ (and via blocking effects in the case of masculine). On the other hand, gender differentiated nouns like dhaska$\operatorname{los}_{M}$ 'teacher' have two uses, without asserted gender and with asserted gender. 
Now we can say the following about the similarities and differences between animal and human nouns.

- Similarities: When a human noun root or an animal noun root has a gender entailment in its assertive meaning, it can combine with a natural gender $n$ (except for neuter human nouns like koritsi 'girl' and agori 'boy', which are required to combine with a grammatical neuter gender; there are no neuter animal nouns with gender inferences).

- Differences: Whenever an animal noun root has a gender-neutral meaning, it cannot combine with a natural gender. The only option is a grammatical gender, and which grammatical gender it is is arbitrarily determined for each root (just as in the case of inanimate nouns). On the other hand, some human noun roots with gender-neutral meaning can still combine with a natural gender $n$, which include dhaskalos ${ }_{M}$ 'teacher' and (either gender of) jatros 'doctor'. These cases, and only these cases, trigger blocking effects.

Why do we have these differences between animal nouns and human nouns? One speculation we can offer is that a natural gender $n$ requires either a gender entailment in the root, or at least a humanness entailment (except when the root requires a grammatical gender). And when a root does not have a gender entailment or a humanness entailment, then it is treated like an inanimate noun. What is special about animal nouns, then, is that they fall in between two extremes - human nouns, which describe entities whose genders are cognitively prominent, on the one hand, and inanimate nouns, which describe entities for which genders do not exist, on the other - and the grammatical system of encoding natural gender only kicks in, when the root entails that gender is relevant at all. If this story is viable, then the difference will boil down to a semantic selectional requirement of a natural gender $n$ on roots.

Perhaps related to this is the fact mentioned at the outset that there are some cases of 'natural gender' among inanimate nouns, although they are arguably unproductive and idiosyncratic, e.g. mela $_{F}$ 'apple' vs. melo $_{M}$ 'apple tree' in Italian. Being closer to inanimate nouns, some animal nouns exhibit such idiosyncratic interpretations, examples which include koraki $_{N}$ 'crow' vs. korakas ${ }_{M}$ 'raven', ghata $_{F}$ 'cat, female cat' vs. ghati ${ }_{N}$ 'kitten'. This unpredictability of interpretation might also play some role in not allowing animal roots with no clear gender entailments to combine with a natural gender $n$.

This idea will explain why we do not see nouns like jatros 'doctor' and dhaskalos $_{M}$ 'teacher' in the domain of animal nouns, but it still won't explain why there is no pair of human nouns like skilos $_{M^{-}}$skila $_{F}$ 'dog', where one of them has a grammatical gender. In Greek, when a human noun has a grammatical gender, as in the case of koritsi $_{N}$ 'girl', there is simply no related form. Our conjecture for this is the following. Human nouns are more 'relevant' in some intuitive sense for human speakers, so let us assume that it is not so costly to come up with morphologically unrelated roots for describe different groups of humans, while it's more costly to coin new morphological roots for describing animals. So the tendency is that the same morphological root of an animal noun is reused for 
different purposes, while human noun roots can have many idiosyncratic properties, including suppletion. Maybe pairs like mitera 'mother' pateras 'father' are those suppletive cases. In the domain of animal nouns, such cases are only limited to animals that are socially and/or culturally very important for human speakers, e.g. kota $_{F}$ 'chicken' vs. kokoras $_{M}$ 'rooster', ajelada ${ }_{F}$ 'cow' vs. tavros ${ }_{M}$ 'bull', katskika 'goat' vs. $\operatorname{traghos}_{M}$ 'buck'. Now, in the domain of human nouns, there is basically no pressure for reusing a root that is used for a grammatical gender with a natural gender $n$. Rather, in that case, a new morphological form will easily be created. It appears that Greek does so systematically.

\section{Concluding Remarks}

In this paper, we started from the idea of markedness among different gender categories with the underlying thesis that masculine is unmarked and semantically vacuous in languages like Greek. Examples such as ghata ${ }_{F}$ 'cat' initially seemed to be problematic for this thesis, but adopting the theoretical view propounded in previous studies, especially, Sudo \& Spathas (to appear) and Spathas (2019), we argued that they can be explained away as cases of grammatical gender. In doing so, we observed non-trivial differences between human nouns and animal nouns. In both domains, grammatical and natural genders are found, but their distributions and properties are not identical, as summarized in the previous section. Admittedly we are far from explaining why such differences exist in Greek, but at least we hope to have made informative empirical observations and offered some speculative thoughts for further studies. We would especially be interested in knowing how animal nouns behave in other languages with nominal gender systems.

\section{References}

Alexiadou, Artemis. 2004. Inflection class, gender and DP-internal structure. In Gereon Müller, Lutz Gunkel \& Gisela Zifonun (eds.). Explorations in Nominal Inflection, 21-50. Berlin: de Gruyter.

Bobaljik, Jonathan \& Cynthia Zocca. 2011. Gender markedness: the anatomy of a counter-example. Morphology 21(2): 141-166. $<$ https://doi.org/10.1007/s11525-010-9156-3>

Breheny, Richard, Nathan Klinedinst, Jacopo Romoli \& Yasutada Sudo. 2018. The symmetry problem: current theories and prospects. Natural Language Semantics 26(2): 85-110. $<$ https://doi.org/10.1007/s11050-017-9141-z>

Comrie, Bernard. 1999. Grammatical gender systems: a linguist's assessment. Journal of Psycholinguistic Research 28(5): 457-466. $<$ https://doi.org/10.1023/A:1023212225540>

Corbett, Greville G. 1991. Gender. Cambridge: Cambridge University Press.

Corbett, Greville G. 2000. Number. Cambridge University Press.

Fathi, Radwa \& Jean Lowenstamm. 2016. The gender assignment pattern of French nouns. Morphology 26: 477-509.

$<$ https://doi.org/10.1007/s11525-016-9287-2> 
Heim, Irene. 2008. Features on bound pronouns. In Daniel Harbour, David Adger \& Susana Be- jar (eds.). Phi Theory: Phi-Features Across Modules and Interfaces, 35-56. Oxford: Oxford University Press.

Jakobson, Roman. 1984. Structure of the Russian verb. In Linda R. Waugh \& Morris Halle (eds.). Russian and Slavic Grammar: Studies 1931-1981, chap. 1, 1-14. Berlin: Mouton.

Katzir, Roni. 2007. Structurally-defined alternatives. Linguistics and Philosophy 30(6): 669- 690 .

$<$ https://doi.org/10.1007/s10988-008-9029-y>

Kiparsky, Paul \& Judith Tonhauser. 2012. Semantics of inflection. In Claudia Maienborn, Klaus von Heusinger \& Paul Portner (eds.). Semantics, vol. 3, 20702097. Berlin: de Gruyter.

Kramer, Ruth. 2014. Gender in Amharic: a morphosyntactic approach to natural and grammatical gender. Language Sciences 43: 102-115. $<$ https://doi.org/10.1016/j.langsci.2013.10.004>

Kramer, Ruth. 2015. The Morphosyntax of Gender. Oxford: Oxford University Press. Landau, Idan. 2016. DP-internal semantic agreement: A configurational analysis. Natural Language and Linguistic Theory 34(3): 975-1020.

Lowenstamm, Jean. 2012. Feminine and gender, or why the 'feminine' profile of French nouns has nothing to do with gender. In E. Cyran, H. Kardela \& B. Szymanek (eds.). Sound Structure and Sense: Studies in Memory of Edmund Gussmann, 371407. Lublin: Wydawnictwo KUL.

Mathieu, Éric. 2012. Flavors of division. Linguistic Inquiry 43(4): 650-679. $<$ https://doi.org/10.1162/ling_a_00110>

Matushansky, Ora. 2013. Gender confusion. In Lisa Cheng \& Norbert Corver (eds.). Diagnosing Syntax, 271-294. Oxford: Oxford University Press.

Merchant, Jason. 2014. Gender mismatches under nominal ellipsis. Lingua 151: 9-32. $<$ https://doi.org/10.1016/j.lingua.2014.01.008>

Murphy, Andrew, Zorica Puškar \& Matías Guzmán Naranjo. 2018. Gender encoding on hybrid nouns in Bosnian/Croatian/Serbian: Experimental evidence from ellipsis. In Denisa Lenertová, Roland Meyer, Radek Šimík \& Luka Szucsich (eds.). Advances in formal slavic linguistics 2016, 313-336. Berlin: Language Science Press.

Percus, Orin. 2011. Gender features and interpretation: a case study. Morphology 21(2): 167- 196.

$<$ https://doi.org/10.1007/s11525-010-9157-2>

Pesetsky, David. 2013. Russian Case Morphology and the Syntactic Categories. Cambridge, MA: MIT Press.

Puškar, Zorica. 2017. Hybrid Agreement: Modelling Variation, Hierarchy Effects and Phi-Features Mismatches: University of Leipzig dissertation.

Puškar, Zorica. 2018. Interactions of gender and number agreement: Evidence from Bosnian/Croatian/Serbian. Syntax 21(3): 275-318.

$<$ https://doi.org/10.1111/synt.12154>

Ralli, Angela. 2000. A feature-based analysis of Greek nominal inflection. Glossolojia 11-12: 201-227.

Sauerland, Uli. 2003. A new semantics for number. In Robert B. Young \& Yuping Zhou (eds.). Proceedings of SALT 13, 258-275. Ithaca, NY: Cornell Linguistics Club. 
Sauerland, Uli. 2008. On the semantic markedness of phi-features. In Daniel Harbour, David Adger \& Susana Béjar (eds.). Phi Theory: Phi-Features across Modules and Interfaces, 57-82. Oxford: Oxford University Press.

Spathas, Giorgos. 2019. On the grammar of nominal gender inferences. Poster presented at GLOW 42 in Oslo.

Stump, Gregory. 2005. Word-formation and inflectional morphology. In Pavol Štekauer \& Rochelle Lieber (eds.). Handbook of Word-formation, 48-71. Dordrecht: Springer.

Sudo, Yasutada \& Giorgos Spathas. to appear. Natural Gender and Interpretation in Greek: Comments on Merchant (2014). Glossa.

Tsimpli, Ianthi Maria \& Aafke Hulk. 2013. Grammatical gender and the notion of default: In- sights from language acquisition. Lingua 137: 128-144.

$<$ https://doi.org/10.1016/j.lingua. 2013.09.001>

Yanovich, Igor. 2012. What can Russian gender tell about the semantics of $q J$-features? Talk at FASL 21. 